Revista Brasileira de Cartografia

ISSN 1808-0936 | https://doi.org/10.14393/revbrascartogr

Sociedade Brasileira de Cartografia, Geodésia, Fotogrametria e Sensoriamento Remoto

\title{
Estimativa da Susceptibilidade à Contaminação do Sistema Aquífero Serra Geral em Aratiba - RS por Diferentes Métodos
}

\author{
Estimation of Susceptibility to the Contamination of the Serra Geral Aquifer System in \\ Aratiba-RS by Different Methods
}

Jean Ricardo Favaretto ${ }^{1}$, Daniel Gustavo Allasia ${ }^{2}$, José Luiz Silvério da Silva ${ }^{3}$, Willian Fernando Borba ${ }^{4}$, Cristiano Niederauer da Rosa ${ }^{5}$ e Gabriel D'Avila Fernandes ${ }^{6}$

1 Universidade Regional Integrada do Alto Uruguai e das Missões, Brasil. E-mail: jeanfavaretto@gmail.com; ORCID: https://orcid.org/0000-0002-6061-9708

2 Universidade Federal de Santa Maria, Brasil. E-mail: dallasia@gmail.com; ORCID: https://orcid.org/0000-0003-4519-8404

3 Universidade Federal de Santa Maria, Brasil. E-mail: silverioufsm@gmail.com; ORCID: http://orcid.org/0000-0003-1712-9145

4 Universidade Federal de Santa Maria, Brasil. E-mail: borbawf@ gmail.com; ORCID: https://orcid.org/0000-0001-5717-1378

5 Programa de Pós-graduação em Sensoriamento Remoto, Universidade Federal do Rio Grande do Sul, Brasil. E-mail:

cristianonrd@gmail.com; ORCID: https://orcid.org/0000-0003-3693-4764

6 Programa de Pós-graduação em Engenharia Civil, Universidade Federal de Santa Maria, Brasil. E-mail:

enggabrielfernandes@gmail.com; ORCID: https://orcid.org/0000-0002-1106-3838

Recebido: 03.2019 | Aceito: 10.2019

Resumo: O abastecimento de água em zonas urbanas e rurais é um problema enfrentado por diversos países. No sul do Brasil, a cidade de Aratiba, representa a realidade dos municípios de pequeno porte do estado do Rio Grande do Sul, em que são abastecidos, quase por completo, por águas subterrâneas. Esta região apresenta alguns problemas que ameaçam a qualidade de suas águas subterrâneas, como o lançamento de efluentes dejetos de suínos e aves de corte sem tratamento, e o uso indiscriminado de agroquímicos. Neste contexto, essa pesquisa teve por objetivo estimar a susceptibilidade do Sistema Aquífero Serra Geral em escala municipal, por meio dos métodos do Índice de Susceptibilidade e Groundwater hydraulic confinement, Overlaying Strata e Deph to groundwater table. Para isso foram utilizadas informações do uso do solo, profundidade da água subterrânea, material do meio aquífero, recarga e topografia. Os resultados apresentaram que o município, tem um IS variando de baixa (27,09\% da área municipal) a elevada (2,29\% da área), com predomínio da classe moderada a baixa (47,24\%). Já o método GOD demostrou uma vulnerabilidade variando de insignificante $(13,54 \%)$ a média $(86,46 \%)$. As metodologias aplicadas apresentaram resultados semelhantes, indicando que o aquífero apresenta condições naturais de proteção, devido a presença de rochas vulcânicas. Contudo, ressalta-se a importância da preservação ambiental, seja em escala local e/ou regional, assim reduzindo os riscos de impactos ao meio, seja ele subterrâneo ou superficial.

Palavras-chave: Água subterrânea. Aquífero fissural. Índice de Susceptibilidade.

\begin{abstract}
The water supply in urban and rural areas is a problem faced by many countries. In southern Brazil, the Brazilian Southern Plateau, the city of Aratiba, is the reality of the small towns of the Rio Grande do Sul state, where both areas are supplied almost entirely by groundwater. This region presents some problems that threaten the quality of their groundwater, such as wastewater discharge waste from pigs and broilers without treatment, and the indiscriminate use of agrochemicals. In this context, this study aimed to estimate the susceptibility of the Serra Geral Aquifer System at the municipal level, through the Susceptibility Index and Groundwater hydraulic confinement, Overlaying Strata, Deph to groundwater table. For this we used information on land use, groundwater depth, aquifer material, recharge and topography. The results showed that the Aquifer System Serra Geral an IS ranging from low $(27,09 \%$ of the municipal area) to high $(2,29 \%$ of the area), with a predominance of moderate class low $(47,24 \%)$. But the GOD system showed a vulnerability ranging from insignificant $(13,54 \%)$ average $(86,46 \%)$, with predominance of the middle class of vulnerability. The results for both methods were similar, indicating that the aquifer has natural conditions of protection due to the presence of volcanic rocks. However, the importance of environmental preservation is emphasized, either locally or regionally, thus reducing the risks of impacts to the environment, whether underground or surface.
\end{abstract}

Keywords: Groundwater. Fissural Aquifer. Susceptibility index. 


\section{INTRODUÇÃO}

A captação de água para o abastecimento dos grandes centros urbanos, em sua maioria, é realizada a partir de recursos hídricos superficiais. Porém, com a crescente contaminação desses recursos, aliado aos custos mais elevados de tratamento, as águas subterrâneas vêm se tornando uma alternativa de menor custo para sanar esse problema. A água subterrânea trata-se de um recurso hídrico renovável em distintas escalas de tempo, dias, meses, anos, séculos (HEATH, 1982), mas a retirada de um volume d'água superior a capacidade de recarga do aquífero traz consigo algumas consequências indesejáveis para o ambiente, como o desequilíbrio do meio e até seu esgotamento, sendo, portanto, um desafio a gestão adequada de seu uso. Além disto, o risco de contaminação dos mananciais subterrâneos é outro entrave, que impossibilita o aquífero de realizar esse abastecimento. Mas quais são os locais mais susceptíveis a contaminação, como situa-los? Nesse sentido, é surgem metodologias que visam promover, não somente a sua gestão adequada, mas também elencar as áreas mais propícias à contaminação, e/ou suas áreas mais protegidas.

Existem diversas metodologias, das quais destacam-se os sistemas Groundwater hydraulic confinement, Overlaying Strata, Deph to groundwater table (GOD), Pollutant Origin and its Surcharge Hydraulically (POSH), ambos descritos por Foster et al. (2002; 2006), e Depth to water, Recharge, Aquifer media, Soil Media, Topography, Impact of the vadose zone, Conductivity of the aquifer (DRASTIC), proposto por Aller et al. (1987).

O sistema GOD (FOSTER et al., 2002; 2006) é amplamente utilizado, por necessitar de informações de apenas das três variáveis G-O-D. Assim, se tem diversos estudos hidrogeológicos utilizando esse método (CUTRIM; CAMPOS, 2010; PINHEIRO et al., 2015; BAES; VILlALBA; NOGUES, 2019; BENABDELOUAHAB et al., 2018). Esse método é de fácil aplicabilidade para as condições hidrogeológicas Brasileiras e Caribenhas (FOSTER et al., 2002; 2006).

Além dos métodos supracitados, o método apresentado por Ribeiro (2005) merece distinção por sua usabilidade. Originário do método DRASTIC (ALLER et al., 1987), o autor retirou algumas variáveis de difíceis estimativa (parâmetros S, I e C), e adicionou o parâmetro LU (Land Use), esse método é conhecido como IS (Índice de Susceptibilidade). Este último foi utilizado por pesquisadores em locais de intenso uso agrícola (PARALTA; FRANCÉS; RIBEIRO, 2005; SERRA et al., 2005; VERÍSSIMO, 2010), os quais destacam que a susceptibilidade do aquífero é um fator essencial para melhor a gestão ambiental, sendo fundamental em planos de reordenamento territorial. O método IS, foi recentemente aplicado no Brasil por Borba et al. (2016) no município de Frederico Westphalen - RS.

Um importante aliado em estudos ambientais é o geoprocessamento, que por tratar-se de uma ciência que se utiliza de ferramentas matemáticas e computacionais para a geração de informações sobre o meio, consegue unir uma grande quantidade de dados apresentando um único e mais completo resultado associado a um Sistema de Informações Geográficas (SIG) capaz de ser especializado em mapas temáticos (MARK, 2003). Com o intuído de avaliar a aplicação de ferramentas de geoprocessamento para mapear, analisar e auxiliar a gestão dos recursos naturais presentes na bacia hidrográfica do Rio Paranaíba em Minas Gerais, Brasil, Flauzino et al. (2010) comprovaram que a aplicação do geoprocessamento, permitiu o conhecimento e a análise das condições ambientais desta importante bacia, possibilitando uma gestão mais adequada dos recursos naturais.

Dentre as tantas ferramentas utilizadas no geoprocessamento, uma das mais conhecidas são os SIG, que reúnem alguns conceitos e técnicas de Geografia, Cartografia, Geodésia, Ciências da Computação, Matemática e Estatística, a algoritmos e modelos, num meio computacional. Permitindo a integração de dados cartográficos, cadastrais de diferentes naturezas, variáveis ambientais, entre outras, em um banco de dados unificado. Refletindo na multiplicidade de seus usos, fornecendo amparo a tomada de decisões nas mais diversas questões do ambiente, caracterizando-o um instrumento articulador importante no processo de integração entre o planejamento ambiental e a gestão dos recursos hídricos (MARTINS et al., 2014; MARK, 2003; WERNECK et al., 2009).

No Brasil as aplicações de ferramentas de geoprocessamento são inúmeras, pode-se citar Padilha et al. (2016), que propuseram uma metodologia para a geração de corredores ecológicos na região de Suape, no Estado de Pernambuco, com o propósito de diminuir o impacto ambiental, gerando resultados relevantes ao 
problema. Outra aplicação pode-se verificada no trabalho de Pinheiro e Souza (2014) que, com o emprego de SIG, determinaram áreas com maior vulnerabilidade a erosão no município de Barra, no Estado da Bahia.

Com base no exposto, este estudo tem por objetivo estimar a susceptibilidade à contaminação do Sistema Aquífero Serra Geral (SASG) em Aratiba, Rio Grande do Sul (RS), por meio da aplicação do IS (RIBEIRO, 2005) e do método GOD (FOSTER et al., 2002; 2006). Fazendo-se uso de ferramentas de geoprocessamento aplicadas a espacialização de informações de poços tubulares, de modo a produzir informações para um melhoramento na gestão do uso do solo na região.

\section{MATERIAL E MÉTODOS}

\subsection{Caracterização da Região em Estudo}

A região de estudo pertence a Bacia Hidrográfica $(\mathrm{BH})$ do Rio Apuaê-Inhandava (U-10) do qual fazem parte 52 municípios (FEPAM, 2016b; SEMA 2004). A principal demanda de água é para o abastecimento público, sendo que a Bacia U - 10 drena suas águas diretamente para o Rio Uruguai (DRH/RS, 2012). Em relação as atividades desenvolvidas na região, tem-se a agricultura (cultivos de milho, trigo e soja), a pecuária, e a suinocultura (FEPAM, 2016a), além da geração de energia (Usina Hidrelétrica de Itá) que exerce importante papel na economia da região. Estima-se também que no local há um rebanho bovino de 29.344 mil cabeças e suíno de 86.746 mil cabeças (IBGE, 2010). Esta região apresenta alguns problemas ambientais como o lançamento de efluentes dejetos de suínos e aves sem tratamento, e o uso indiscriminado de agrotóxicos (FEPAM, 2016a)

O Município de Aratiba, está localizado na porção noroeste do Estado do Rio Grande do Sul, com área de aproximadamente $346 \mathrm{~km}^{2}$, pertencente a região do Alto Uruguai Gaúcho, conforme mostra a Figura 1. Possui uma população estimada em 6.565 habitantes, sendo 3.249 residentes na zona rural e 3.316 na zona urbana (IBGE, 2010). Destaca-se que este estudo se foca no referido município pela carência de informações ambientais no local, e em especial pelas características geográficas que se assemelham a muitos municípios do território Brasileiro.

Segundo dados de saneamento básico do Ministério da Saúde, das 2.165 famílias que residem no município, $55 \%$ são abastecidas pela rede pública, que atualmente é administrada pela Companhia Riograndense de Saneamento (CORSAN). O abastecimento é, em sua grande maioria, realizado por poços tubulares (Figura 2), na zona urbana eles são administrados pela CORSAN. Na zona rural são, basicamente, administrados por sociedades comunitárias compostas por grupos de agricultores, que compartilham as águas captadas pelos poços, os demais, são abastecidos por fontes ou nascentes (ARATIBA, 2015).

Nesse órgão licenciador são listados, como atividades antrópicas (possíveis causadoras de impacto ambiental), 58 cadastros de criação de aves de corte e 120 de criação de suínos, terminação, com manejo de dejetos (FEPAM, 2016b). Nesta Bacia Hidrográfica alguns municípios tais como: Erechim, Machadinho, Marcelino Ramos e Três Arroios apresentam potencial hidrotermal associado a Zona de Forte Confinamento do Sistema Aquífero Guarani (SAG) (PSAG/OEA/PEA, 2009) em poços profundos, superiores a $500 \mathrm{~m}$. Os afloramentos pertencem as rochas vulcânicas da Formação Serra Geral constituindo o SASG, aquífero do tipo fissural.

Se tratando da hidrogeologia local, no município tem-se o SASG I (sg1) e II (sg2), conforme Figura 3. Segundo Machado e Freitas (2005), o sistema sg1 constitui-se principalmente de litologias basálticas, amigdalóides e fraturadas, capeadas por espesso solo avermelhado. Referindo-se ao sistema sg2, os mesmos autores afirmam que este é localizado na parte oeste do Estado do RS, nos limites das rochas vulcânicas com o Rio Uruguai e as litologias gonduânicas, além de uma extensa área no nordeste do planalto da Serra Geral, associada com os derrames da Unidade Hidroestratigráfica Serra Geral. Suas litologias são constituídas predominantemente por rochas ácidas (teores de $\mathrm{SiO}_{2}$ maiores do que $65 \%$ ) riólitos, riodacitos e em menor proporção, basaltos fraturados básicos (teores de $\mathrm{SiO}_{2}$ entre 45 e $52 \%$ ), conforme Leinz e Amaral (1980).

Nota-se a predominância do sg2, com produtividade dos aquíferos ruim (MACHADO; FREITAS, 2005) somente na porção norte do município, junto a calha do Rio Uruguai ocorre o sg1 de baixa produtividade. Tendo em vista essas produtividades pequenas dos aquíferos, e dadas as condições da orografia local, esses 
não são utilizados na irrigação de culturas.

Figura 1 - Localização do Município de Aratiba na Bacia Hidrográfica U-10, Norte do Estado.

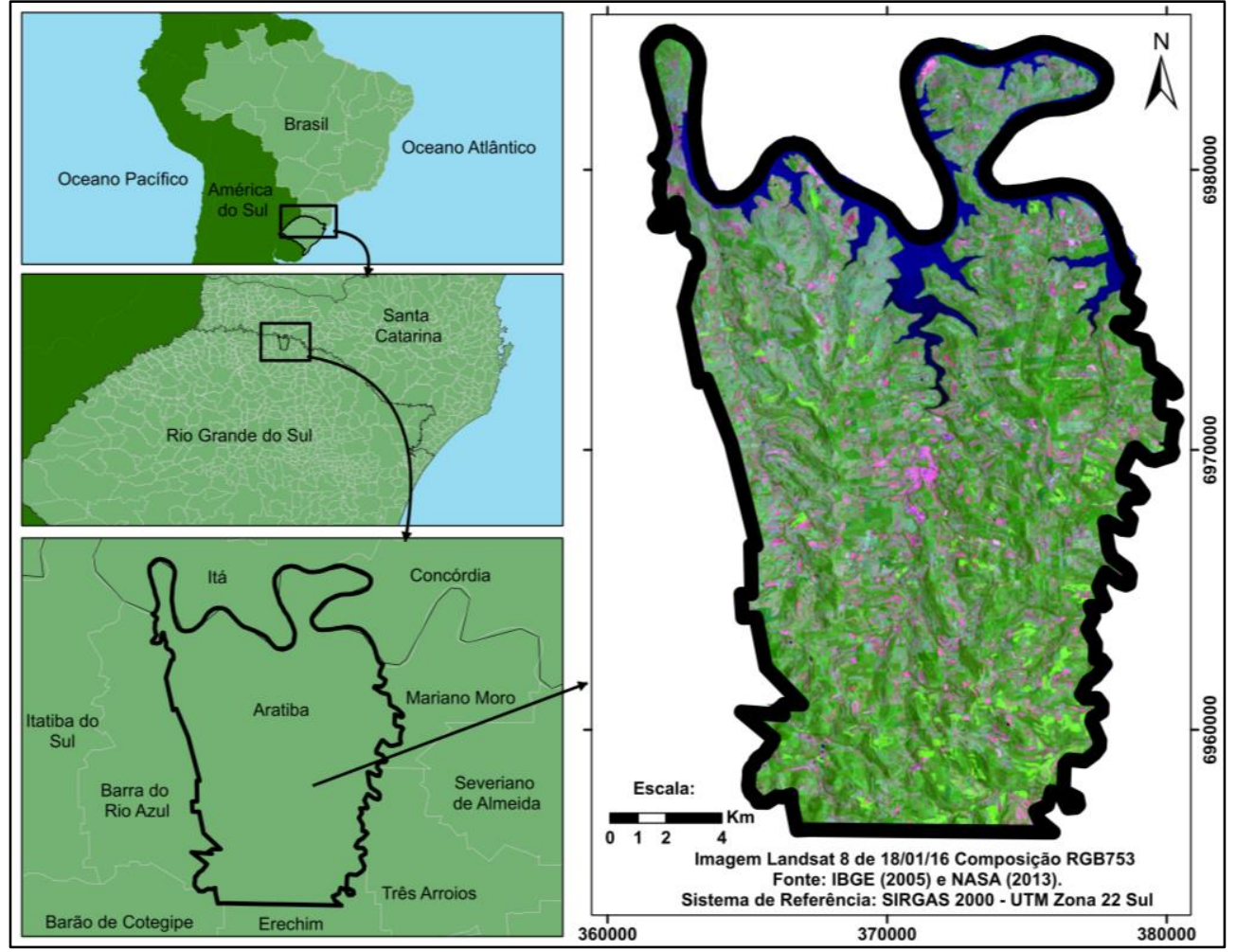

Fonte: Os autores (2020).

Figura 2 - Localização dos poços tubulares na paisagem do município de Aratiba/RS.

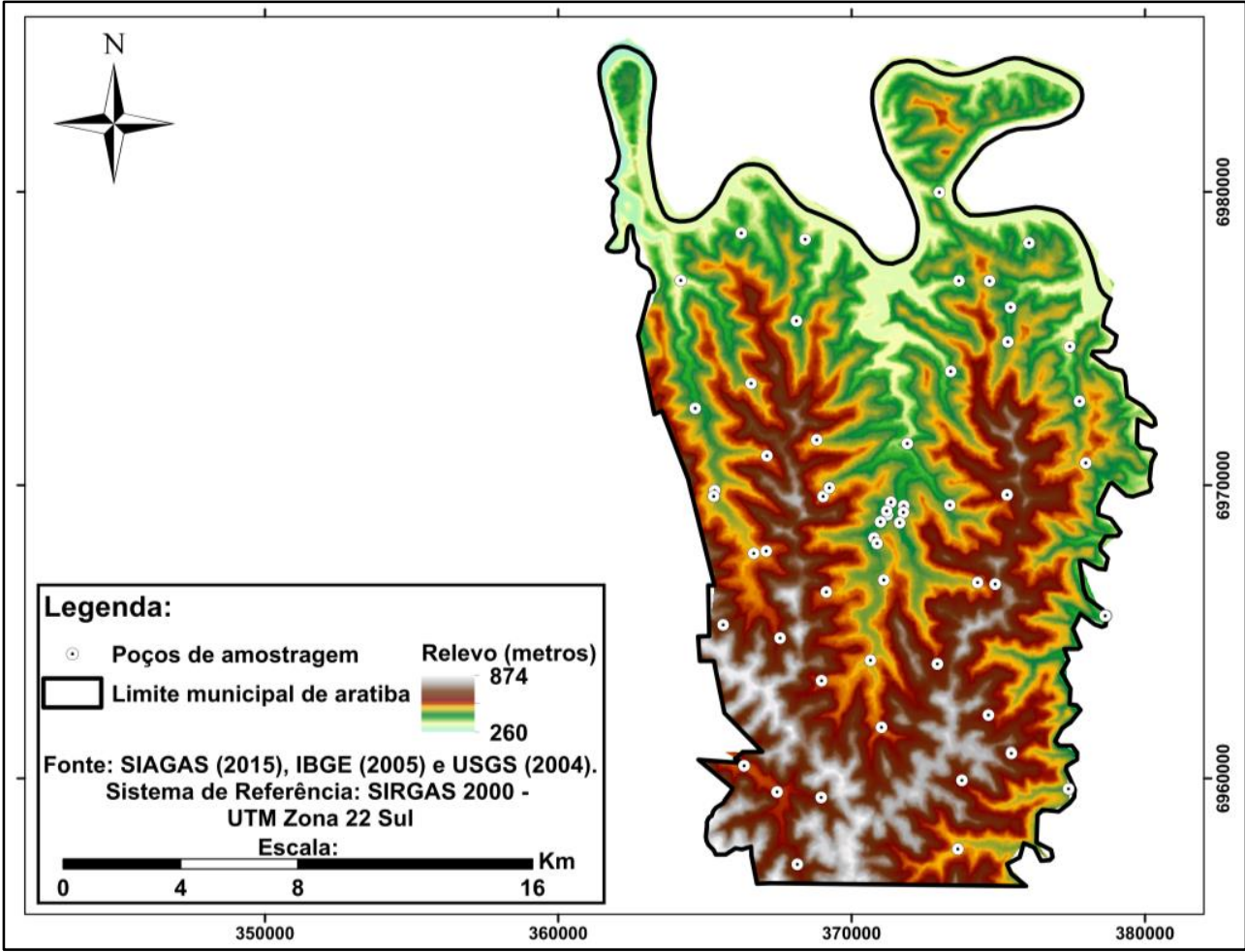

Fonte: Os autores (2020). 
Já em relação a geologia, o município está inserido na Formação Serra Geral (Fsg), Fácies Paranapanema (k1_beta_pr), conforme Figura 3. Essa unidade, segundo a Companhia de Pesquisa de Recursos Minerais (CPRM, 2006), é caracterizada pela ocorrência de derrames basálticos granulares finos, melanocráticos, contendo horizontes vesiculares, espessos preenchidos com quartzo (ametista), zeólitas, carbonatos, seladonita, cobre nativo e barita.

Figura 3 - Hidrogeologia (A) e Geologia (B) presente em Aratiba/RS.

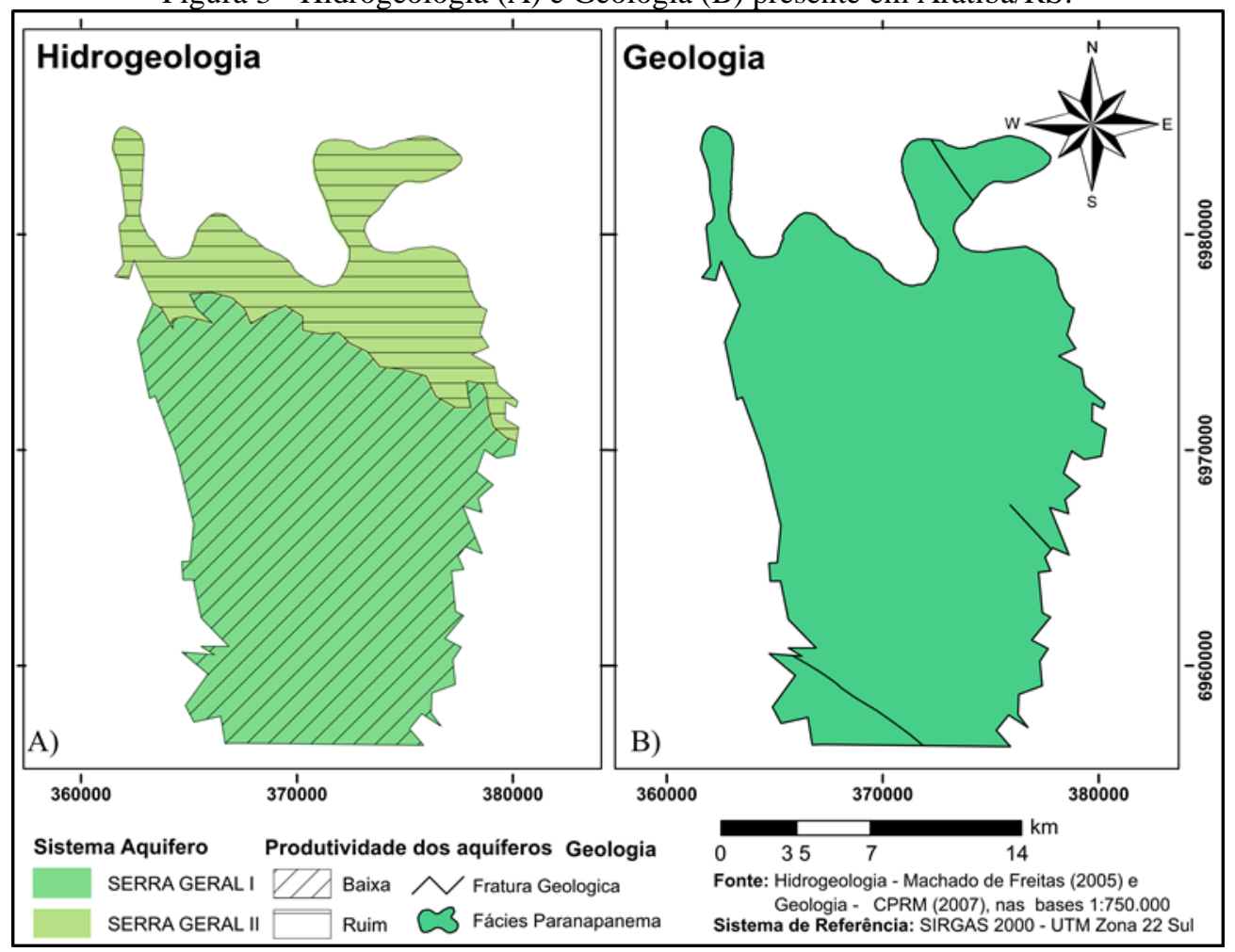

Fonte: Os autores (2020).

\subsection{Determinação do IS (RIBEIRO, 2005) e vulnerabilidade do aquífero à contaminação pelo método GOD (FOSTER et al., 2002; 2006)}

Perante a quantidade de informações consideradas no estudo, foi utilizado a versão 10.3. do sistema de gerenciamento de banco de dados geográfico ArcGIS@ (ESRI, 2019), o qual, permitiu o acesso, a edição e a manipulação dos dados utilizados na pesquisa.

Para a estimativa da recarga subterrânea do SASG na região de estudo, foram utilizados os valores propostos por Hausman (1995). Considerando-se a precipitação média anual de $1.800 \mathrm{~mm}$ e uma recarga média anual de cerca de $125 \mathrm{~mm}$, obtendo-se um valor de 6,9\% de recarga anual.

Para a determinação do material do aquífero e a distância do nível freático/estático, foram utilizadas as informações do banco de dados do Sistema de Informações de Águas Subterrâneas (SIAGAS), gerenciado pela CPRM do Serviço Geológico do Brasil (SIAGAS, 2015). Campanhas de medições de nível de água não foram realizadas, sendo essa variável a mesma de quando ocorreram as perfurações dos poços. Assim, utilizouse as informações de 123 poços tubulares, localizados nos munícipios gaúchos de Aratiba (57 poços cadastrados no SIAGAS), Barra do Rio do Azul (21 poços), Itatiba do Sul (9 poços) e Mariano Moro (36 poços). Foram utilizadas as informações destes municípios devido a quantidade de poços pertencentes a área de estudo específica não representar de forma satisfatória, sua totalidade e uma vez nem todos os poços continham as informações necessárias as aplicações dos métodos. Além disso, foi seguido o proposto por Costa et al. (2011).

Assim, as informações de profundidade, recarga e material do aquífero obtidas conforme supracitado pontualmente, foram espacializadas para posterior estimativa de seus valores em locais não amostrados, isto foi possível com o emprego de um modelo geoestatístico de Krigagem. Este interpolador, além de considerar distribuição espacial dos pontos, também leva em conta o comportamento estatístico do fenômeno interpolado, 
tendências amostrais e de sentidos preferenciais do fenômeno. Os parâmetros do modelo interpolação foram otimizados seguindo a metodologia abordada por Johnston et al. (2001). A escolha desse método de interpolação justifica-se, pois, sua empregabilidade para o mapeamento de sistemas aquíferos demostra-se satisfatória como pode ser visto em Aboufirassi e Marino (1983) e Alamy Filho e Segantini (2010), constituindo-se numa importante ferramenta para a gestão dos aquíferos. Mazzini e Schettini (2009) salientam que esse método apresenta grande vantagem sobre outros interpoladores.

O uso do solo foi obtido a partir de uma imagem multiespectral datada de janeiro de 2016, por representar a condição mais severa do ano (maior percentagem de solo exposto em função da colheita agrícola na região), sem a presença de nuvens, pertencente a missão Landsat 8, com resolução espacial de 30 metros (NASA, 2013). As bandas espectrais de 1 a 7 foram compostas numa única imagem. Essa foi submetida a um processo de classificação supervisionada por meio da ferramenta Raster Classification (MaxVer), considerando as seguintes classes: Ambientes aquáticos, áreas urbanas, florestas e zonas seminaturais, pastagens e áreas agroflorestais.

Os resultados da classificação de uso do solo foram avaliados a partir da matriz de confusão, por meio da qual foi calculado o coeficiente de concordância Kappa (ANTUNES; LINGNAU, 1997), cuja concordância foi classificada conforme Landis e Koch (1977), e o índice de exatidão global. Para tal foram gerados 136 pontos aleatoriamente e obtidas as verdades de campo a partir de imagens do Google Earth.

As declividades (em porcentagem) foram geradas com base nas imagens da missão Shuttle Radar Topography Mission (SRTM), de resolução espacial de 30 metros (USGS, 2004). Ambas imagens estão disponíveis em: earthexplorer.usgs.gov.

Para a determinação das variáveis D, R e T, as quais integram o método IS (RIBEIRO, 2005), foram utilizadas as informações contidas nas Tabelas 1, 2 e 3, respectivamente. Já as variáveis A e LU, estão ilustradas nas Tabelas 4 e 5, respectivamente.

Tabela 1- Parâmetro D do IS (Ribeiro, 2005) e sua respectiva pontuação.

\begin{tabular}{c|c}
\hline \multicolumn{2}{c}{$\mathbf{D}$} \\
\hline Profundidade (m) & Pontuação \\
\hline$<1,5$ & 10 \\
$1,5-4,6$ & 9 \\
$4,6-9,1$ & 7 \\
$9,1-15,2$ & 5 \\
$15,2-22,9$ & 3 \\
$22,9-30,5$ & 2 \\
$>30,5$ & 1 \\
\hline \multicolumn{2}{c}{ Fonte: Os autores (2020). }
\end{tabular}

Tabela 2- Parâmetro R do IS (Ribeiro, 2005) e sua respectiva pontuação.

\begin{tabular}{c|c}
\hline \multicolumn{2}{c}{$\mathbf{R}$} \\
\hline Recarga (mm/ano) & Pontuação \\
\hline$<51$ & 1 \\
$21-102$ & 3 \\
$102-178$ & 6 \\
$178-254$ & 8 \\
$>254$ & 9 \\
\hline
\end{tabular}

Fonte: Os autores (2020). 
Tabela 3- Parâmetro T do IS (Ribeiro, 2005) e sua respectiva pontuação.

\begin{tabular}{c|c}
\hline \multicolumn{2}{c}{ T } \\
\hline Declividade (\%) & Pontuação \\
\hline$<2$ & 10 \\
$2-6$ & 9 \\
$6-12$ & 5 \\
$12-18$ & 3 \\
$>18$ & 1 \\
\hline \multicolumn{2}{c}{ Fonte: Os autores (2020). }
\end{tabular}

Tabela 4 - Parâmetros A do IS (Ribeiro, 2005) e suas respectivas pontuações.

\begin{tabular}{|c|c|c|}
\hline \multicolumn{3}{|l|}{$\mathbf{A}$} \\
\hline Natureza do aquífero & Pontuação & Usual \\
\hline Xisto argiloso, argilito & $01-03$ & 2 \\
\hline Rocha metamórfica/ígnea & $02-05$ & 3 \\
\hline Rocha metamórfica/ígnea alterada & $03-05$ & 4 \\
\hline Till glacial & $04-06$ & 5 \\
\hline Arenito, calcário e argilito estratificados & $05-09$ & 6 \\
\hline Arenito maciço & $04-09$ & 6 \\
\hline Calcário maciço & $04-09$ & 8 \\
\hline Areia a basalto & $04-08$ & 8 \\
\hline Basalto & $02-10$ & 9 \\
\hline Calcário carstificado & $09-10$ & 10 \\
\hline
\end{tabular}

Fonte: Adaptada de Aller et al. (1987).

Tabela 5 - Parâmetros LU do IS (Ribeiro, 2005) e suas respectivas pontuações.

\begin{tabular}{|c|c|}
\hline \multicolumn{2}{|l|}{$\mathbf{L U}$} \\
\hline Ocupação do solo & Pontuação \\
\hline Áreas agrícolas & \\
\hline Perímetro de rega (Culturas anuais..) & 90 \\
\hline Culturas permanentes (vinhas...) & 70 \\
\hline Pastagem e áreas agroflorestais, áreas agrícolas heterogêneas & 50 \\
\hline Áreas artificiais & \\
\hline Descargas de resíduos artificiais e aterros & 100 \\
\hline Pedreiras e estaleiros, áreas minerais a céu aberto & 80 \\
\hline Áreas urbanas contínuas, aeoroportos & 75 \\
\hline Áreas urbanas descontínuas & 70 \\
\hline Áreas naturais & \\
\hline Ambientes aquáticos (sapais, salinas..) & 50 \\
\hline Florestas e zonas semi-naturais & 0 \\
\hline
\end{tabular}

Fonte: Construído a partir de Ribeiro (2005).

As informações de profundidade, declividade, recarga, material do aquífero e uso do solo, foram reclassificadas conforme os valores indicados nas Tabelas 1 a 5 com o emprego da ferramenta Reclassify. Os valores de D, R, A e T, foram exagerados em 10 vezes, conforme sugerido por Veríssimo (2010). Este autor indica, que com essa extrapolação, ocorre uma melhor visualização das variáveis, quando comparadas ao parâmetro LU. Assim, a determinação do IS foi obtida a partir da Eq. (1) cujas constantes de ponderação da equação foram sugeridas por Ribeiro (2005), tal equação foi sistematizada por meio da ferramenta Raster calculator. A classificação final do IS é apresentada na Tabela 6. 


$$
I S=0,186 D+212 R+0,256 A+0,121 T+0,222 L U
$$

Para a determinar o quão vulnerável à contaminação o aquífero é, foi utilizado o método GOD (FOSTER et al., 2002; 2006), sendo que o índice de vulnerabilidade é obtido a partir do produto das variáveis G, O e D. Esse índice é classificado como insignificante (valores de 0 a 0,1$)$, baixo $(0,1$ a 0,3$)$, médio $(0,3$ a $0,5)$, alto $(0,5$ a 0,7$)$ e extremo $(0,7$ a 1,0$)$.

Tabela 6 - Classificação final do IS.

\begin{tabular}{c|c}
\hline Valores (\%) & Vulnerabilidade \\
\hline$>90$ & Extremamente vulnerável \\
$80-90$ & Muito elevada \\
$70-80$ & Elevada \\
$60-70$ & Moderada a alta \\
$50-60$ & Moderada a baixa \\
$40-50$ & Baixa \\
$30-40$ & Muito baixa \\
$<30$ & Extremamente baixa \\
\hline
\end{tabular}

Fonte: Adaptada de Stigter et al. (2006).

\section{RESULTADO E DISCUSSÃO}

\subsection{Profundidade do nível freático $(D)$ e recarga $(R)$}

A Figura 4 -Parâmetros D (A) e R (B) para o município de Aratiba/RS (A) e (B), juntamente com a Tabela 7 ilustram os parâmetros D e R, e suas respectivas notas. As zonas mais escuras do mapa da Figura 4A, ilustram os menores níveis de profundidade de água subterrânea, correspondendo as maiores pontuações. Sendo que, quanto mais superficial for o nível da água no aquífero (menores valores de nível estático), maior será a sua susceptibilidade à contaminação por um contaminante que ocorra na superfície do terreno de origem antrópica. Já em relação a recarga, esse baixo valor se deve principalmente a geologia, as litologias presentes, onde a recarga ocorre somente nas fraturas das rochas vulcânicas (ácidas e/ou básicas) que representa baixos valores. Esse fato também foi explicado por Machado e Freitas (2005), onde os aquíferos presentes na área de estudo representam produtividade ruim e baixa (Figura 3).

Tabela 7 - Pontuação dos parâmetros D e R.

\begin{tabular}{c|c|c|c}
\hline $\mathbf{D}(\mathbf{m})$ & Pontuação & $\mathbf{R}(\mathbf{m m})$ & Pontuação \\
\hline$<1,5$ & 100 & & \\
$1,5-4,6$ & 90 & & \\
$4,6-9,1$ & 70 & & \\
$9,1-15,2$ & 50 & 125 & 60 \\
$15,2-22,9$ & 30 & & \\
$22,9-30,5$ & 20 & & \\
$>30,5$ & 10 & \\
\hline
\end{tabular}

Fonte: Adaptada de Aller et al. (1987) e Ribeiro (2005). 
Figura 4 -Parâmetros D (A) e R (B) para o município de Aratiba/RS.

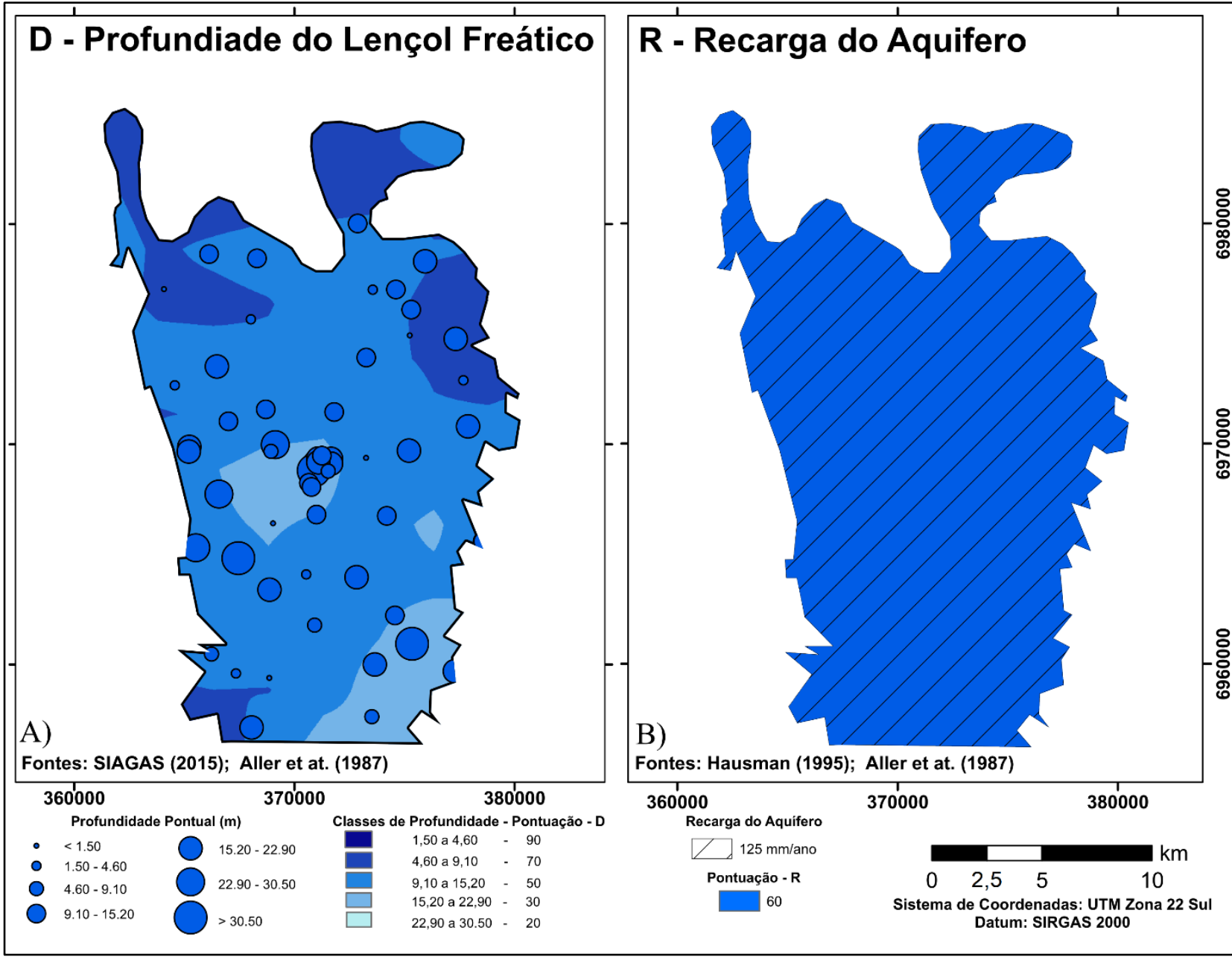

Fonte: Os autores (2020).

\subsection{Material do aquífero (A) e topografia (T)}

A Figura 5 (A) e (B), juntamente com a Tabela 8 contém os parâmetros A e T, e suas respectivas notas. No que diz respeito ao material do aquífero, conforme descrito pela CPRM (2006), é constituído por rochas vulcânicas e os produtos de sua intemperização.

A topografia no local, faz parte do Planalto Meridional Brasileiro e apresenta-se bastante movimentada, variando entre cotas altimétricas de 259 e $875 \mathrm{~m}$ acima do nível médio do mar, Oceano Atlântico, Porto de Imbituba no Estado de Santa Catarina, como pode ser observado na Figura 2. Sendo a altitude média no local em torno dos $420 \mathrm{~m}$, as declividades obtidas são da ordem de 0 a $109 \%$, sendo que $66,24 \%$ da área total da cidade tem declividade maior do que 18,00\%.

Tabela 8 - Pontuação dos parâmetros A e T.

\begin{tabular}{c|c|c|c}
\hline A & Pontuação & T (\%) & Pontuação \\
\hline \multirow{3}{*}{ Basalto } & & $2-6$ & 100 \\
& \multirow{3}{*}{90} & $6-12$ & 90 \\
& & $12-18$ & 50 \\
& & $>18$ & 30 \\
& & 10 \\
\hline
\end{tabular}

Fonte: Adaptada de Aller et al. (1987) e Ribeiro (2005). 
Figura 5 - Parâmetros A (A) e T (B) para o município de Aratiba/RS.

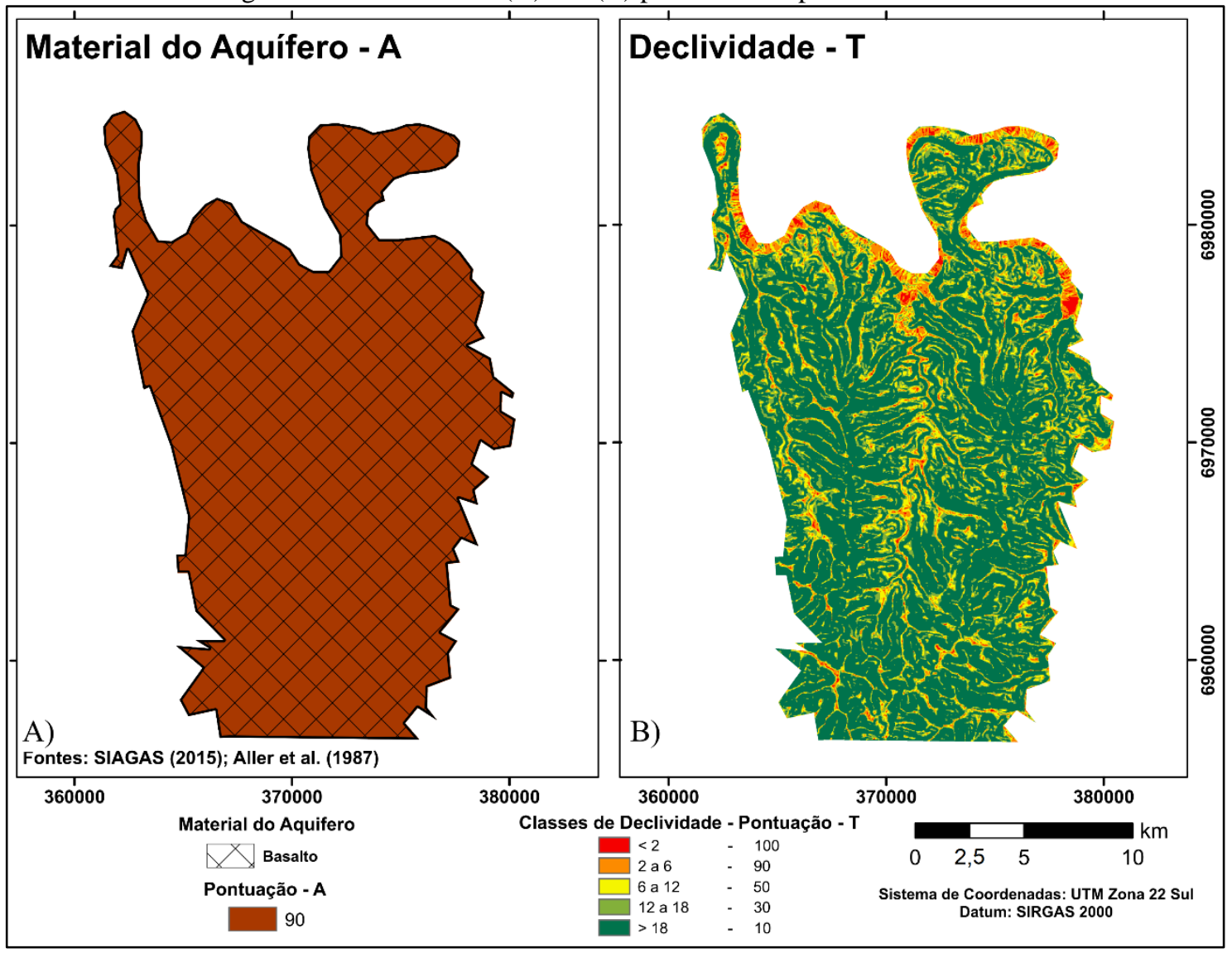

Fonte: Os autores (2020).

\subsection{Land Use (LU)}

O uso do solo predominante na região é de pastagens e áreas agroflorestais, onde representa 59,70\%, enquanto as áreas de florestas e zonas semi-naturais se fazem presentes em cerca de 30,14\% do local de estudo, e são seguidas de ambientes aquáticos $9,00 \%$ e área urbana aproximadamente 1,00\%, conforme ilustra a Figura 6. Na Tabela 9 é descrita a pontuação do parâmetro LU. A avaliação da acurácia da classificação do uso do solo apresentou coeficiente kappa com concordância classificada como muito boa (kappa $=0,72)$ e índice de exatidão global de 0,83 .

Tabela 9 - Pontuação do parâmetro LU.

\begin{tabular}{c|c}
\hline $\boldsymbol{L} \boldsymbol{U}$ & Pontuação \\
\hline$\underline{\text { Áreas agrícolas }}$ & $\underline{50}$ \\
Pastagem e áreas agroflorestais, áreas agrícolas heterogêneas & 50 \\
$\underline{\text { Áreas artificiais }}$ & $\underline{75}$ \\
Áreas urbanas contínuas, aeoroportos & $\underline{75}$ \\
Áreas naturais & $\underline{50}$ \\
Ambientes aquáticos (sapais, salinas) & 0 \\
Florestas e zonas semi-naturais & 0
\end{tabular}

Fonte: Adaptada de Ribeiro (2005). 
Figura 6 - Parâmetro LU para o município de Aratiba/RS.

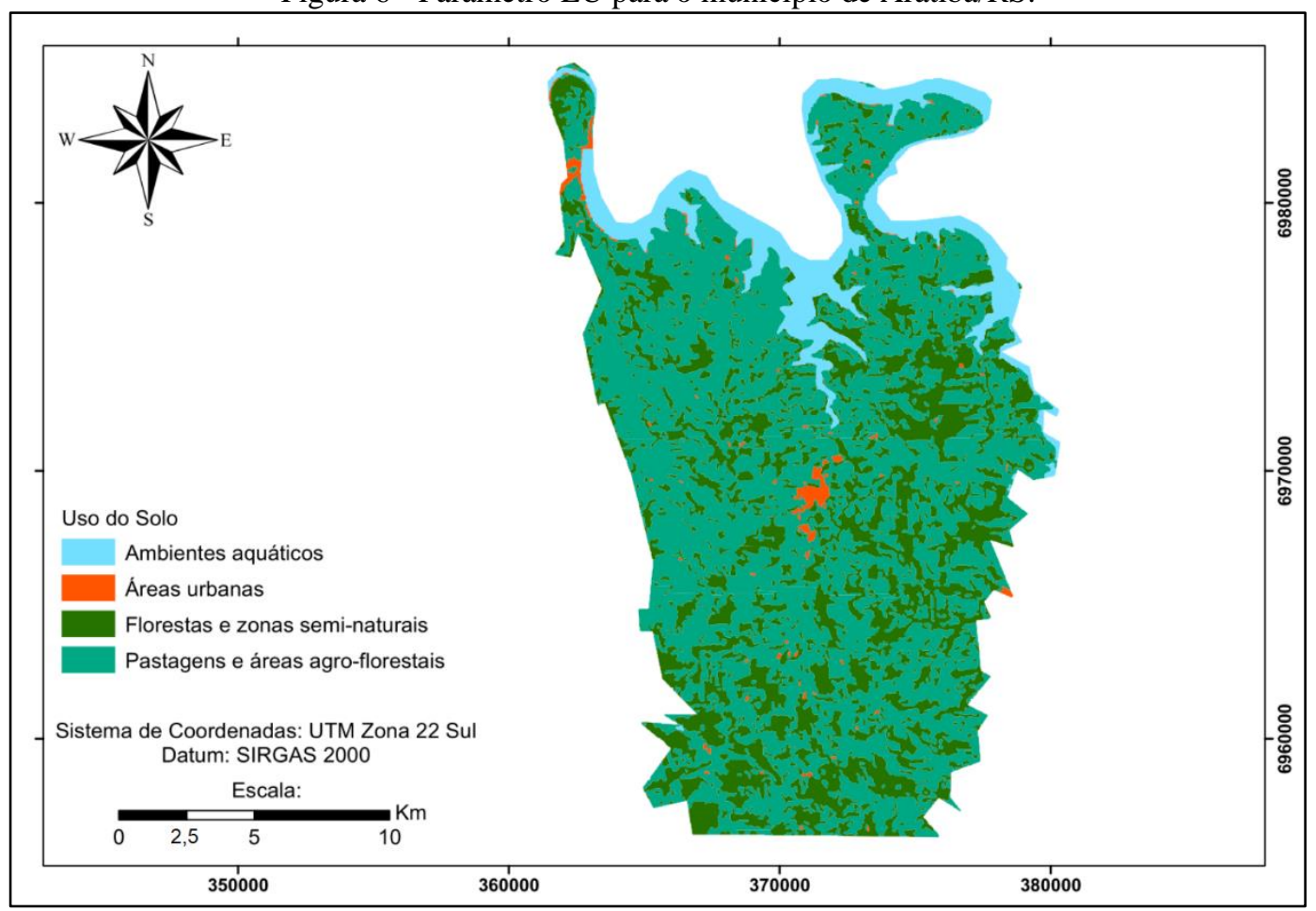

Fonte: Os autores (2020).

\subsection{Estimativa da vulnerabilidade pelo IS (RIBEIRO, 2005) e pelo método GOD (FOSTER et al., 2002; 2006)}

A partir da estimativa do IS (RIBEIRO, 2005), os resultados estão ilustrados na Figura 7 A. Estudos voltados a essa temática, são de suma importância, principalmente em regiões onde estão localizadas atividades que podem causar impacto ao meio ambiente, principalmente subterrâneo. Sendo assim, na região de estudo, destaca-se, segundo dados do IBGE (2010) e FEPAM (2016a; 2016b), atividades ligadas a criação de suínos, e aves de corte, além da agricultura intensiva. Sendo que dessas atividades, a suinocultura por exemplo, gera efluentes líquidos, que muitas vezes são utilizados na fertirrigação de cultivos agrícolas. Nesse caso, segundo Merten e Minella (2002), a contaminação pode ocorrer quando a quantidade de efluente lançado no solo, extrapola a capacidade desse meio e das plantas, absorverem esses nutrientes. Além dos efluentes dos suínos e aves de corte, nos cultivos agrícolas (soja, milho e trigo), utilizam-se fertilizantes químicos a base de Nitrogênio, Fósforo e Potássio (NPK), os quais em cargas excessivas, podem comprometer a qualidade dos recursos hídricos (superficiais e/ou subterrâneos). Porém, esse processo pode ser atenuado quando as características do meio (Geologia e solos, por exemplo) apresentam condições de maior proteção. Nesse mesmo sentido, como limitação do método, esse não classifica as fontes pontuais como cemitérios, indústrias e postos de combustíveis, sendo que, nesses casos é necessário a aplicação de métodos complementares, como o POSH (FOSTER, et al., 2002; 2006), por exemplo.

O IS (RIBEIRO, 2005) apresentou valores que variaram de 40 a $80 \%$, entre as classes baixa a elevada, conforme a Figura 7 A. mediante os resultados do IS notou-se que na área do município ocorreu a predominância da classe moderada a baixa, presente em 47,27 \% de seu território, conforme visto na Tabela 10. As áreas mais vulneráveis à contaminação estão localizadas nas proximidades da calha do Rio Uruguai, onde destacam-se os valores de 23,00\% do território pertencente a classe de susceptibilidade moderada a alta. No que refere-se aos estudos portugueses que utilizaram o IS (RIBEIRO, 2005), Paralta, Francés e Ribeiro (2005) e Stigter, Vieira e Nunes (2002) encontraram classes variando entre média e alta (65 a $75 \%$ ) no Sistema Aquífero Gabros de Beja e na região do Algarve, respectivamente. Veríssimo (2010) encontrou valores entre extremamente baixa e moderada a alta (20 a 65,5\%) no Aquífero de Torres Vedras. 


\begin{tabular}{cc} 
Tabela 10 - Áreas estimadas a partir do método IS. \\
\hline Classes de IS & Área $\mathbf{( \% )}$ \\
\hline Baixa & 27,09 \\
Moderada a baixa & 47,24 \\
Moderada a alta & 23,36 \\
Elevada & 2,29 \\
\hline
\end{tabular}

Fonte: Os autores (2020).

Figura 7 - Estimativa da suscetibilidade do aquífero em Aratiba/RS: A) Estimativa da vulnerabilidade pelo IS (RIBEIRO, 2005) e B) Estimativa da vulnerabilidade a partir do método GOD (FOSTER et al., 2002; 2006).

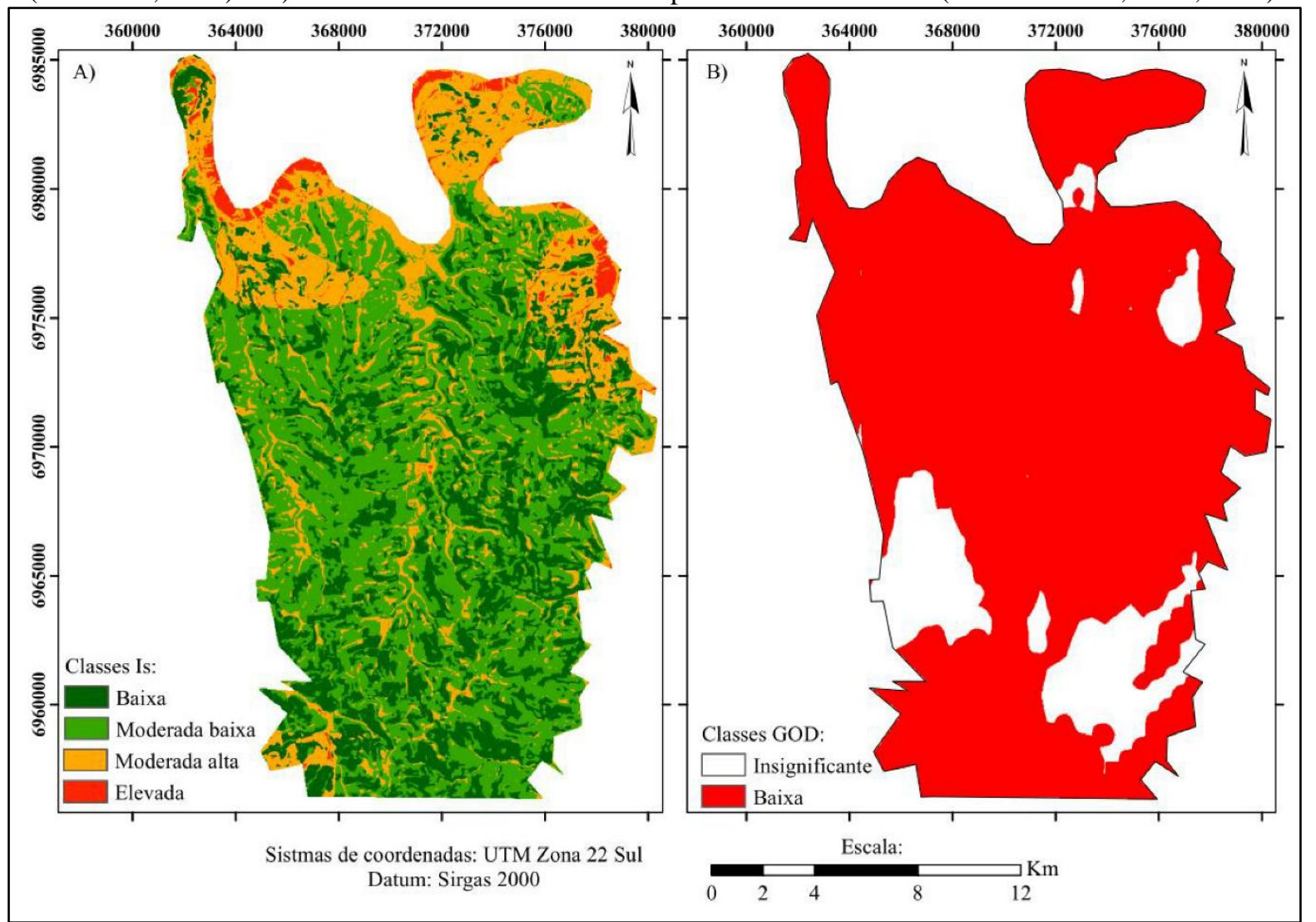

Fonte: Os autores (2020).

Em relação a vulnerabilidade natural do aquífero à contaminação, a Figura 7 B, ilustra a classificação utilizando o método GOD (FOSTER et al., 2002; 2006) para o município de Aratiba (RS) pertencente ao SASG, aquífero fissural. Como pode ser observado, as classes de vulnerabilidade variaram de insignificante (valores de 0,0 a 0,1$)$ a baixa $(0,1$ a 0,3$)$, sedo esta última encontrada em $86,46 \%$ da área pesquisada. $\mathrm{Na}$ área de estudo, está presente o SASG, sendo este um aquífero formado por rochas vulcânicas e seus produtos de intemperização. Nesse sentido, Nanni et al. (2005) salientam que esse aquífero apresenta características fissurais, desenvolvendo ao longo de fraturas e descontinuidades, sendo que a circulação de água nessas fraturas está quase sempre sob pressão. Assim, pode-se ter poços com artesianismo nessa unidade hidroestratigráfica.

O SASG I e II (Figura 3), por meio de suas características geológicas, naturais ou intrínsecas, proporcionam uma melhor proteção natural ao meio subterrâneo, visto que, na maioria das vezes, encontra-se sob confinamento por essas rochas vulcânicas. Rosa Filho et al. (2006) dizem que no SASG o volume produzido de água, difere de local para local, sendo regulada pela recarga natural, sendo assim a locação dos poços tubulares deve ser realizada buscando penetrar as descontinuidades geológicas. Porém, nessas zonas de recarga (fraturas das rochas vulcânicas) podem representar um grave problema hidrogeológico, visto que o contaminante pode entrar em contato direto com a água subterrânea e assim espalhar-se com maior facilidade.

Estudos que utilizaram essa metodologia em áreas do SASG encontraram o predomínio de classes de vulnerabilidade variando de insignificante a média (NANNI et al., 2005; FREITAS; BINOTTO; NANNI, 
2012; REGINATO; ALHERT, 2013; SILVÉRIO DA SILVA et al., 2013; BORBA et al., 2015), sendo estas encontradas na presente pesquisa.

\subsection{Comparativo da estimativa da vulnerabilidade a partir da aplicação dos métodos GOD e IS}

A partir da Tabela 11 e da Figura 8, pode ser observado a porcentagem de área para cada uma das classes de vulnerabilidade, resultante do emprego do método GOD (FOSTER et al. 2002; 2006) e IS (RIBEIRO, 2005). Ocorreu a predominância da classe moderada a baixa para o método IS e da classe baixa com a aplicação do método GOD.

Tabela 11 - Estimativa de áreas quanto a classe de vulnerabilidade para o método GOD (Foster et al., 2002; 2006) e IS

\begin{tabular}{|c|c|c|c|}
\hline Classes GOD & Área (\%) & Classes IS & Área (\%) \\
\hline \multirow[b]{2}{*}{ Insignificante } & \multirow[b]{2}{*}{13,54} & Baixa & 27,09 \\
\hline & & Moderada a Baixa & 42,24 \\
\hline \multirow{2}{*}{ Baixa } & \multirow{2}{*}{86,46} & Moderada a Alta & 23,36 \\
\hline & & Elevada & 2,29 \\
\hline
\end{tabular}

Fonte: Os autores (2020).

Figura 8 - Comparativo da estimativa da suscetibilidade do aquífero em Aratiba/RS pelo IS (RIBEIRO, 2005) e GOD (FOSTER et al., 2002; 2006)

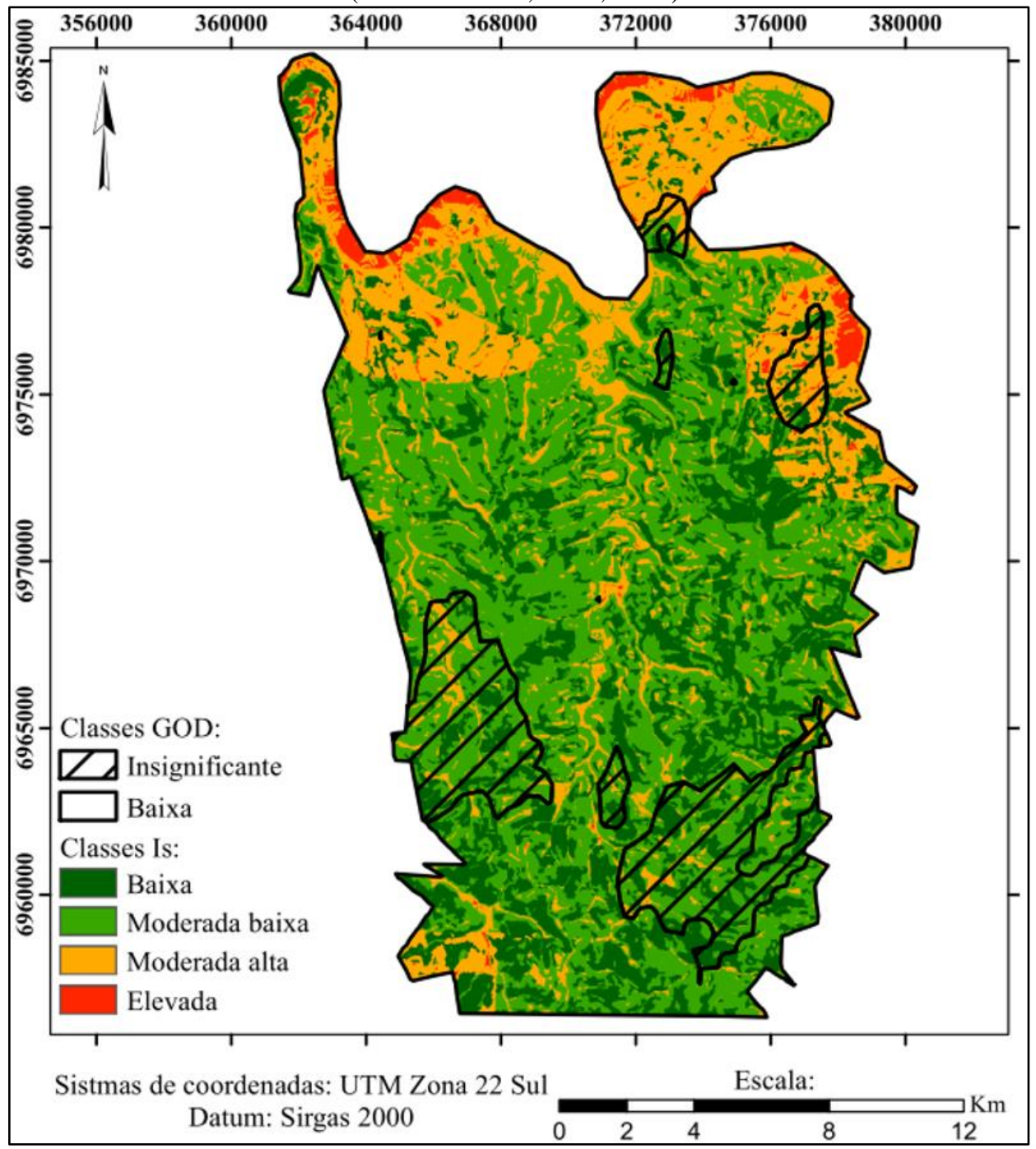

Fonte: Os autores (2020).

Como pode ser observado na Figura 8, as menores classes de vulnerabilidade (Insignificante e baixa) estão localizadas nas áreas menos susceptíveis a contaminação (Baixa e moderada). Isso indica que os métodos 
fornecem resultados semelhantes para as áreas com menor potencial de impacto no meio subterrâneo. Não obstante, o método IS por apresentar uma maior gama de parâmetros de análise, fornece resultados mais detalhados. Isso é identificado pela presença das classes de susceptibilidade alta e elevada, as quais representam cerca de $25 \%$ da área.

\section{CONCLUSÕES}

A utilização de ambos os sistemas para a estimativa da vulnerabilidade e susceptibilidade à contaminação do SASG, aquífero fissural, mostrou-se eficiente para a região de estudo. Foi possível identificar-se que o IS apresentou valores superiores quando comparado ao método GOD em algumas classes de susceptibilidade. Isso pode ser devido a maior gama de parâmetros do IS, que pode apresentar valores superiores. Porém, o IS apresentou predomínio da classe moderada a baixa, sendo que esse fato também foi obtido com uso do método GOD.

Outro fato a ser observado foi que o IS fornece uma descrição mais detalhada da vulnerabilidade do aquífero, sendo, portanto, um melhor descritor para tal finalidade. Assim, esses estudos podem ser utilizados para fundamentar o desenvolvimento de planos diretores, ambientais ou ainda em escala de bacia hidrográfica, evitando que atividades com potencial de contaminação do aquífero fiquem locadas em áreas vulneráveis, por exemplo. Recomenda-se a realização de estudos complementares, como os que classificam as atividades conforme o potencial de contaminação, que visem melhorar e substanciar os resultados estimados nessa pesquisa, tornando ainda mais fundamentados os resultados obtidos.

É importante destacar que o método tem uma empregabilidade em para a gestão municipal, pois não considera condições específicas, como densidade e grau de faturamento das rochas, por exemplo.

Sugere-se que em estudos futuros sejam feitas verificações de campo para comprovar a eficácia dos métodos empregados, assim como o efeito da utilização de diferentes escalas de informação.

\section{Agradecimentos}

Os autores agradecem a Coordenação de Aperfeiçoamento de Pessoal de Nível Superior - Brasil (CAPES) - Código de financiamento 001 e ao Conselho Nacional de Desenvolvimento Científico e Tecnológico $(\mathrm{CNPq})$ pelo fomento ao desenvolvimento desta pesquisa.

\section{Contribuição dos Autores}

As contribuições de cada autor para desenvolvimento deste trabalho são: conceptualização, análise forma, investigação e redação - revisão e edição, Jean Ricardo Favaretto; conceptualização, investigação, metodologia e redação - minuta inicial, redação e edição, Cristiano Niederauer da Rosa; conceptualização, investigação, metodologia e redação - minuta inicial, Willian Fernando Borba; conceptualização, investigação, validação e redação - minuta inicial, Gabriel D'Avila Fernandes; conceptualização, metodologia, redação revisão e edição, e supervisão, Daniel Gustavo Allasia; e conceptualização, metodologia, redação - revisão e edição, e supervisão, José Luiz Silvério da Silva.

\section{Conflitos de Interesse}

Os autores declaram que não há conflitos de interesse.

\section{Referências}

ALLER, L.; BENNETT, T.; LEHR, J. H.; PETTY, R.J.; HACKETT G. DRASTIC: A standardized system for evaluating ground water pollution potential using hydrogeologic settings. Chicago: Environmental Protection Agency, 1987.

ALAMY FILHO, J. E.; SEGANTINI, M. de O. Mapeamento do Sistema Aquífero Bauru subjacente à cidade 
de Araguari-MG. In: CONGRESSO BRASILEIRO DE ÁGUAS SUBTERRÂNEAS, 16, 2010, São

Luís - MA. Anais... São Luis: Associação Brasileira de Águas Subterrâneas, 2010. p. 1-15.

ABOUFIRASSI, M.; MARINO, M. A. Kriging of water levels in the Souss Aquifer, Morocco.

Mathematical Geology, vol. 15, n. 4, p. 537 - 551. 1983.

ANTUNES, A.F.B., LINGNAU, C. 1997. Uso de índices de acurácia para avaliação de mapas temáticos obtidos por meio de classificação digital. In: CONGRESSO E FEIRA PARA USUÁRIOS DE GEOPROCESSAMENTO, 3., 1997, Curitiba. Anais... Curitiba: Sagres, 1997.

ARATIBA. Prefeitura Municipal Aratiba. Transparência Municipal de 2008 - 2015. Disponível em $<$ http://www.pmaratiba.com.br>. Acessado em março 2015.

BAES, L.; VILLALBA, C.; NOGUES, J. B. Comparison of contaminant-specific risk maps for an urban aquifer: Patiño aquifer case. Environmental Earth Sciences, vol. 78, n. 137, p. 1 - 15. 2019.

BENABDELOUAHAB, Sara et al. Using resistivity methods to characterize the geometry and assess groundwater vulnerability of a Moroccan coastal aquifer. Groundwater for Sustainable Development, v. 7, p. 293-304, 2018.

BORBA, W. F.; SILVÉRIO DA SILVA, J. L.; ALLASIA, D. G.; ROSA, C. N.; FAVARETTO, J. R.; RIBEIRO, L. F. T. Geoprocessamento Aplicado à Determinação do Índice de Susceptibilidade das Captações por Poços Tubulares do Sistema Aquífero Serra Geral em Frederico Westphalen - Rio Grande do Sul. Anuário do Instituto de Geociências (UFRJ. Impresso), v. 39, p. 79 - 88. 2016.

BORBA, W. F.; TERRA, L. G.; FERNANDES, G. D. A.; FRANCA, J. R.; GANZER, E. P.; MANCUSO, M. A.; SILVÉRIO DA SILVA, J. L. Determinação da vulnerabilidade natural à contaminação do Aquífero Serra Geral em Frederico Westphalen - RS. In: SIMPÓSIO BRASILEIRO DE RECURSOS HÍDRICOS, 21., 2015,Brasília. Anais... Brasília: Associação Brasileira de Recursos Hídricos, 2015. p. $1-15$.

COSTA, M. L. M. C.; COSTA, M. M. R. R.; REGO, J. C. R.; ALBURQUERQUE, J. do P. T. Preposição de critérios de outorga para águas subterrâneas. Revista Brasileira de Recursos Hídricos, Porto Alegre, v. 16, n. 1, p. 105 - 113. 2011.

CPRM, Companhia de Pesquisa de Recursos Minerais. Mapa Geológico do Rio Grande do Sul, escala 1:750.000. Brasília: CPRM/SIAGAS, 2006.

CUTRIM, A. O.; CAMPOS, J. E. G. Avaliação da vulnerabilidade e perigo à contaminação do aquífero Furnas na cidade de Rondonópolis (MT) com aplicação dos métodos GOD E POSH. Geociências, v. 29, p. $401-411.2010$.

CÂMARA, G.; DAVIS, C.; MONTEIRO, A. M. V. Introdução à Ciência da Geoinformação. São José dos Campos: INPE, 2001.

DRH (Departamento de Recursos Hídricos) - Estado do Rio Grande do Sul. Relatório Anual sobre a Situação dos Recursos Hídricos no Estado do Rio Grande do Sul. DRH, Porto Alegre: DRH, 2012.

ESRI - Maps throughout this book were created using ArcGIS@® software by Esri. ArcGIS® and ArcMap $^{\mathrm{TM}}$ are the intellectual property of Esri and are used herein under license. Copyright $(\subset)$ Esri. All rights reserved. For more information about Esri ${ }^{\circledR}$ software, please visit: http://www.esri.com. 2019.

FEPAM, Fundação Estadual de Proteção Ambiental. Região Hidrográfica do Rio Uruguai. 2016a. Disponível em <http://www.fepam.rs.gov.br/qualidade/regiao_uruguai.asp >. Acessado em fevereiro 2016.

FEPAM, Fundação Estadual de Proteção Ambiental. Atividades antrópicas cadastradas em Aratiba. 2016b. Disponível em <http://www.fepam.rs.gov.br/qualidade/municipio.asp?cod=4300901\&regiao=U10>. Acessado em abril 2016.

FOSTER, S.; HIRATA, R. C. A.; GOMES, D.; D’ELIA, M.; PARIS, M. Proteção da qualidade da água subterrânea: um guia para empresas de abastecimento de água, órgãos municipais e agências ambientais. Washington: World Bank, 2006.

FOSTER, S.; HIRATA, R. C. A.; GOMES, D.; D’ELIA, M.; PARIS, M. Groundwater quality protection: a guide for water utilities, municipal authorities, and environment agencies. Washington: World 
Bank, 2002.

FLAUZINO, F. S.; SILVA, M. K. A.; NISHIYAMA, L.; ROSA, R. Geotecnologias aplicadas à gestão dos recursos naturais da Bacia Hidrográfica do Rio Paranaíba no Cerrado Mineiro. Revista Sociedade \& Natureza, Uberlândia, v. 1, n. 22, p. 75 - 91. 2010.

FREITAS, M. A.; BINOTTO, R. B.; NANNI, A. S. Avaliação do potencial hidrogeológico, vulnerabilidade intrínseca e hidroquímica do Sistema Aquífero Serra Geral no noroeste do Estado do Rio Grande do Sul. Revista Brasileira de Recursos Hídricos, Porto Alegre, v. 17, n. 2, p. 31 - 41. 2012.

HAUSMAN, A. Esboço Hidrogeológico do Rio Grande do Sul. Revista Acta Geologica Leopoldensia, p. 37 - 71.1995.

HEATH, R. C. Basic ground-water Hydrology. USGS: Water Supply paper 2240, 1982.

IBGE, Instituto Brasileiro de Geografia e Estatística. Censo demográfico 2010. Disponível em $<$ http://censo2010.ibge.gov.br/>. Acessado em março 2015.

JOHNSTON, K.; VER HOEF, J. M.; KRIVORUCHKO, K.; LUCAS, N. Using ArcGIS geostatistical analyst. United States of America: Esri Redlands, 2001. p. 300.

LANDIS, J.; KOCH, G. G. The measurements of agreement for categorical data. Biometrics, Washington, v. 33, n. 3, p. 159 - 179. 1977.

LANDIM, P. M. B. Introdução aos métodos de estimação espacial para confecção de mapas: Rio Claro: DGA/IGCE/UNESP, 2000.

LEINZ, V.; AMARAL, S. E. do. Geologia Geral. São Paulo: Editora Nacional, 1980. 543p.

MACHADO, J. L. F.; FREITAS, M. A. Projeto mapa hidrogeológico do Estado do Rio Grande do Sul: escala 1:750.000, relatório final. Porto Alegre: CPRM, 2005.

MARK, D. M. Geographic information science: Defining the field, In: DUCKHAM, M., GODCHILD, M. F.; WORBOYS, M. F. Foundations of geographic information science. 1 ed. London: Taylor \& Francis, p. 3 - 18. 2003.

MARTINS, E. M.; FORTES, J. D. N.; RIBEIRO, G. P.; PEREIRA, M. F. M. Utilização de Sistema de informação geográfica como ferramenta para gestão do monitoramento da qualidade do ar na Região Metropolitana do Rio de Janeiro. Revista Engenharia Sanitária e Ambiental, Rio de Janeiro, n. 19, p. 43 - 49, 2014.

MERTEN, G. H.; MINELLA, J. P. G. Qualidade da água em bacias hidrográficas rurais: um desafio atual para a sobrevivência futura. Revista Agroecologia e Desenvolvimento Rural Sustentável, Porto Alegre, v. 3, n. 4, p. 33 - 38. 2002.

NASA, National Aeronautics and Space Administration, Landsat Program. Landsat ETM+ cena LC82220792016018LGN00, L1T, USGS, Sioux Falls. Disponível em $<$ http://earthexplorer.usgs.gov>. Acessado em fevereiro de 2016.

NANNI, A. S.; TEDESCO, M. A.; FREITAS, M. A.; BINOTTO, R. B. 2005. Vulnerabilidade natural e risco de contaminação do Aquífero Serra Geral pela suinocultura na região das missões - RS. In: SIMPÓSIO BRASILEIRO DE RECURSOS HÍDRICOS, 16., 2005, João Pessoa. Anais... João Pessoa: Associação Brasileira de Recursos Hídricos, 2005. p. 1-19.

PARALTA, E.; FRANCÉS, A.; RIBEIRO, L. F. Avaliação da vulnerabilidade do Sistema Aquífero dos Gabros de Beja e análise crítica das redes de monitorização no contexto da directiva quadro da água. In: SIMPÓSIO DE HIDRÁULICA E RECURSOS HÍDRICOS DOS PAÍSES DE LÍNGUA OFICIAL PORTUGUESA, 7., 2005, Évora. Anais... Évora, 2005. p 1 - 16.

PADILHA, P.; PORTUGAL, J. L.; SANTOS, A. V.; PEREIRA, S. V.; CARMO, T. V. B. Proposição de modelo de corredores ecológicos com base no Sistema de Informações Geográficas na região de Suape, Pernambuco, Brasil. Revista Brasileira de Geografia Física, Recife, v. 9, n .1, p. 79 - 90. 2016.

PINHEIRO, L.; SOUZA, D. Análise da vulnerabilidade à erosão no município de Barra - Bahia. Revista Geonorte, Manaus, v. 10, n. 1, p. 10 - 15. 2014.

PINHEIRO, R. J. B.; RAUBER, A. C. R.; NUMMER, A. V.; SILVÉRIO DA SILVA, J. L. Aplicação dos Métodos GOD e POSH para determinação da vulnerabilidade e perigo à contaminação dos aquíferos na cidade de Santa Maria - RS. Revista de Gestão de Água da América Latina, v. 12, n. 2, p. 61 - 
79. 2015.

REGINATO, P. A. R.; AHLERT, S. Vulnerabilidade do Sistema Aquífero Serra Geral na Região Nordeste do Estado do Rio Grande do Sul. Revista Águas Subterrâneas, São Paulo, v. 27, n. 2, p. 32 - 46. 2013.

RIBEIRO, L. F. Um novo índice de vulnerabilidade específico de aquíferos - formulações e aplicações. In: SIMPÓSIO DE HIDRÁULICA E RECURSOS HÍDRICOS DOS PAÍSES DE LÍNGUA OFICIAL PORTUGUESA, 7., 2005, Évora. Anais... Évora, 2005. p 1 - 16.

ROSA FILHO, E. F. DA.; HINDI, E. C.; MANTOVANI, L. E.; BITTENCOURT, A. V. L. A importância do Sistema Aquífero Serra Geral para a cultura da soja no Estado do Paraná. Revista Águas Subterrâneas, São Paulo, v. 20, n. 2, p. 49 - 56. 2006.

SEMA, Secretaria de Meio Ambiente - Estado do Rio Grande do Sul. Mapa das bacias hidrográficas. Porto Alegre: SEMA/DRH, 2004.

SERRA, E. M.; PARALTA, E.; NASCIMENTO, J. N.; RIBEIRO, L. F. Análise comparativa de dois índices de poluição agrícola no sistema Aquífero dos Gabros de Beja (sector da margem esquerda do Rio Guadiana). JORNADAS LUSO-ESPANHOLAS SOBRE ÁGUAS SUBTERRÂNEAS NO SUL DA PENÍNSULA IBÉRICA., 2003 Faro. Anais... Faro. 2003.

SILVÉRIO DA SILVA, J. L.; DESCOVI FILHO, L. L. V.; LORENSI, R. P.; CRUZ, J. C.; ELTZ, F. L. Vulnerabilidade do Aquífero Serra Geral à contaminação no município de Erechim - Rio Grande do Sul - Brasil. Revista Ciência e Natura, Santa Maria, v. 35, n. 1, p. 10 - 23. 2013.

SIAGAS, Sistema de Informações de Águas Subterrâneas. Companhia de Pesquisa de Recursos Minerais. Pesquisa geral. 2015. Disponível em <http://siagasweb.cprm.gov.br/layout/>. Acessado em maio de 2015.

STIGTER, T.; VIEIRA, J.; NUNES, L. Avaliação da Susceptibilidade à Contaminação das águas Subterrâneas no Apoio à Tomada de Decisão, Caso de Estudo: Implantação de Campos de Golfe no Concelho de Albufeira (Algarve). In: CONGRESSO NACIONAL DA ÁGUA, 6., 2002, Porto.

Anais... Porto: Associação Portuguesa dos Recursos Hídricos, 2002.

STIGTER, T. Y.; RIBEIRO, L.; CARVALHO DILL, A. M. M. Evaluation of an intrinsic and a specific vulnerability assessment method in comparison with groundwater salinisation and nitrate contamination levels in two agricultural regions in the south of Portugal. Hydrogeology Journal, v. 14, n. 1 , p. 79 - 99. 2006.

USGS,United States Geological Survey. Shuttle Radar Topography Mission, 1 Arc Second scene SRTM1S28W054V3, Unfilled Unfinished 2.0, Global Land Cover Facility, University of Maryland, College Park, Maryland. 2004. Disponível em 〈http://earthexplorer.usgs.gov〉. Acessado em fevereiro de 2015.

VERÍSSIMO, A. C. F. Hidroquímica, vulnerabilidade e protecção do Aquífero de Torres Vedras. 2010. Dissertação de Mestrado. Curso de Pós-graduação em engenharia geológica e de minas, Universidade de Lisboa/Instituto Superior Técnico, Lisboa, 2010. 140p.

ZANIN, E. M. Caracterização e diagnóstico ambiental da paisagem urbana de Erechim. Edifapes: Erechim, 2002.

WERNECK, B. R.; PINHEIRO, M. R. C.; OLIVEIRA, A. F.; MOTÉ, F.; MARÇAL, M. S.; SILVA, J. A. F.; FERREIRA, M. I. P. Geoprocessamento aplicado à gestão dos recursos hídricos na bacia hidrográfica do Rio Macaé - RJ. In: SIMPÓSIO BRASILEIRO DE SENSORIAMENTO, 14., 2009, Natal. Anais... Natal: Instituto Nacional de Pesquisas Espaciais, 2009. p. 4247 - 4254. 


\section{Biografia do autor principal}

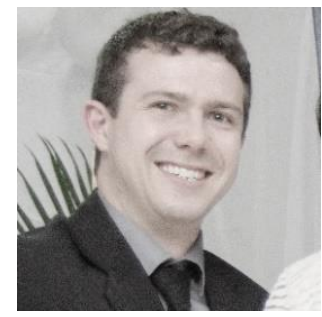

Jean Ricardo Favaretto, natural de Aratiba, RS - Brasil. Possui graduação em Engenharia Civil pela Universidade Federal de Santa Maria (2014) e mestrado em Engenharia Civil pela Universidade Federal de Santa Maria (2016). Tem experiência na área de Engenharia Civil, com ênfase em Geomática e Recursos Hídricos. Atualmente é Coordenador e Professor do Curso de Engenharia Civil na Universidade Regional Integrada do Alto Uruguai e das Missões (URI), campus de Frederico Westphalen - RS.

Esta obra está licenciada com uma Licença Creative Commons Atribuição 4.0 Internacional - CC BY. Esta licença permite que outros distribuam, remixem, adaptem e criem a partir do seu trabalho, mesmo para fins comerciais, desde que lhe atribuam o devido crédito pela criação original. 